\title{
Potential of SWOT for monitoring water volumes in Sahelian ponds and lakes
}

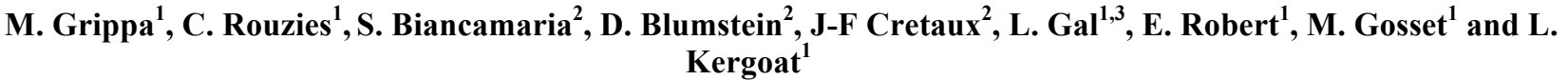 \\ 1 : Géosciences Environnement Toulouse (GET) \\ 2 : Laboratoire d'études en géophysique et océanographie spatiales (LEGOS) \\ 3 : Laboratoire d'étude des Interactions entre Sol-Agrosystème-Hydrosystème (LISAH)
}

\begin{abstract}
Small water bodies play a pivotal role in Sahel, as a critical source of water for livestock and people, and providers of important ecosystems services. Monitoring, modelling and better understanding their hydrological behaviour is therefore a key issue. The future Surface Water and Ocean Topography (SWOT) satellite mission will bring a resolution and spatial coverage breakthrough, allowing the estimation of water levels and volumes in small water bodies worldwide. This study assesses the potential of SWOT for monitoring water volumes in Sahelian ponds and lakes. This is done by analysing SWOT-like synthetic data produced using a SWOT simulator developed by NASA-JPL. For the Agoufou lake, water levels were retrieved with an accuracy better than $4 \mathrm{~cm}$, while slightly worst results were obtained for the Zalam-Zalam lake, that has a more elongated shape. In addition, data from the Global Precipitation Mission Dual-frequency Precipitation Radar have been also employed to investigate the backscattering coefficient variability in the same radar frequency band (Ka-band) as SWOT. We have found that, in the study region, the contrast between water and land, dependent on soil type, soil moisture, and wind conditions, is sometime quite small which can be challenging for water masks estimation. Overall, the first application of the SWOT simulator over the Sahel has shown the good potential of SWOT for monitoring the seasonal variability of water levels and volumes in this region.
\end{abstract}

\section{Index Terms - SWOT, inland water, Sahel, lakes}

\section{INTRODUCTION}

Small water bodies play a pivotal role in the Sahel as they provide a critical water resource for livestock and people. They have an important impact on the ecosystems in terms of biodiversity and emission of greenhouse gases as well as an influence on the spread of water-borne diseases. They are also very reactive to climate and human forcing and develop complex and sometimes unexpected dynamics, as the paradoxical increase of surface water [1] and runoff [2, 3] during and after the big multi-decadal Sahelian drought. In addition surface water represent a fundamental resource for cattle breeding, agricultural activities and domestic uses. Surface water remains highly used even in the presence of water supplies or pumps [4].

Monitoring, modelling and better understanding the hydrological behavior of these small water bodies is therefore a key issue. However, it has not been much addressed up to now given, on the one hand, the scarce in-situ data availability in these poorly instrumented regions and, on the other hand, the high spatial resolution necessary to quantify water amounts from satellite sensors.If mapping water areas has been successfully achieved at different spatio-temporal resolutions using optical $[1,5,6]$ or radar [7, 8] remote sensing sensors, deriving water levels and volumes is more challenging.

In the last decades, classical nadir altimetry techniques have been increasingly used to derive water levels over inland waters [9] but, usually, only large lakes falling on the satellite tracks can be monitored (see for example the HYDROWEB G-REALM and DAHITI databases [10, 11, 12]). One exception is the work by Baup et al. [13] that showed the possibility of monitoring water volumes in a small lake in the south of France by combining optical and radar high resolution imagery and classical altimetry data by the RA-2 sensor on board ENVISAT.

Alternative approaches have been developed to derive information on Sahelian and west African water bodies. They combine water areas derived by optical or radar remote sensing (spanning few hectares to several square kilometers) to area-volumes relationships available from in-situ bathymetry or a priori assumptions on the shape of these water bodies $[2,14,15,16,17,18]$. Despite the good results obtained, it remains difficult to extrapolate this kind of approaches at a regional scale, given that volume-area relationships can vary significantly among different lakes (see for example fig. 6 in [2]).

The Surface Water and Ocean Topography (SWOT) satellite mission [19], planned for launch in 2021, will bring a spatial coverage and resolution breakthrough in altimetry 
allowing monitoring water levels and volumes in small water bodies throughout the world.

The SWOT main payload is a Ka-band Radar Interferometer (KaRIn) instrument [19, 20], with incident angles between $0.6^{\circ}$ and $4.1^{\circ}$. The expected performances for lakes will allow retrieving water level with a vertical resolution better than $10 \mathrm{~cm}$ on water bodies of $1 \mathrm{~km}^{2}$ area $[21,22]$. This is a new concept and this kind of instrument has not been flown yet on any space borne platform.

The objective of the present study is to assess the potential of SWOT for monitoring water volumes in Sahelian ponds and lakes. The Sahelian region can be challenging for remote sensing given the poorly documented and highly variable values in surface characteristics (water roughness, soil type and soil moisture) impacting the radar backscattering coefficients [23, 24] and the wide range of atmospheric moisture content [25] that can affect the propagation of electromagnetic waves in the atmosphere [26]. Simulations can be used to investigate some of these issues before launch. Few studies up to now have employed synthetic SWOT data to assess SWOT potential for monitoring lakes and reservoirs [27, 28, 29, 30]. Especially, [30] studied benefits from SWOT-like observations to manage reservoirs in the upper Niger basin. However, SWOT errors were modeled with a white noise applied to water elevations. Our work is the first one addressing the Sahel and more generally semi-arid regions using realistic SWOT observations.

\section{STUDY AREA AND DATA SETS}

\section{1. Study area and in-situ measurements}

The study area is the Gourma region (Fig.1), in northern Mali, typical of pastoral areas in central Sahel [31]. It is instrumented by the AMMA-CATCH observatory [32] that collects data on hydro-meteorological and ecological variables, including water level [2], turbidity and suspended sediments [13].

The spatio-temporal variability of water bodies in this region has been already assessed using optical remote sensing approaches. Gardelle et al. [1] investigated the long term evolution in water areas showing a spectacular increase in ponds and lakes area over the last 50 years, despite the precipitation decrease over the same period. Gal et al [2], coupled lake areas derived by optical remote sensing to insitu measurements of water levels to estimate volumes changes in the Agoufou lake. They, then, applied a lake water balance equation to estimate water inflow over the watershed from water volume changes, precipitation and evaporation. This allowed quantifying runoff over the watershed, a critical variable to calibrate and evaluate land surface and hydrological models [34, 35] which greatly helped to better understand the mechanisms responsible for the Sahelian paradox in this region.

Robert et al. [33], also using optical remote sensing analyzed turbidity and suspended particulate matter (SPM) in the Gourma ponds and lakes. They found that the SPM dynamics is driven by the convective precipitation of the West African monsoon, but re-suspension mechanisms, driven by wind with lake water level and lake area that impact the fetch, also play a significant role during the dry season.

This study adresses in particular the Agoufou and the Zalam-Zalam lakes (see Fig.1), to span different shapes (round for Agoufou, elongated for Zalam-Zalam). Water areas vary significantly between the dry and the wet season with minima at about 100 ha and maxima at about 250 ha for both lakes [1]. Water level seasonal variations are about $2 \mathrm{~m}$ [1]. For both lakes the filling up is quite rapid and it is driven by the monsoon precipitation mostly occurring between July and September. Water maxima are reached at the end of the wet season in October and then the lakes empty mostly by evaporation at a rate of about $7 \mathrm{~mm} /$ day. They are both on sandy soils and receive runoff from shallow soils located on their watersheds (represented in gray-blue colors in Fig. 1). 


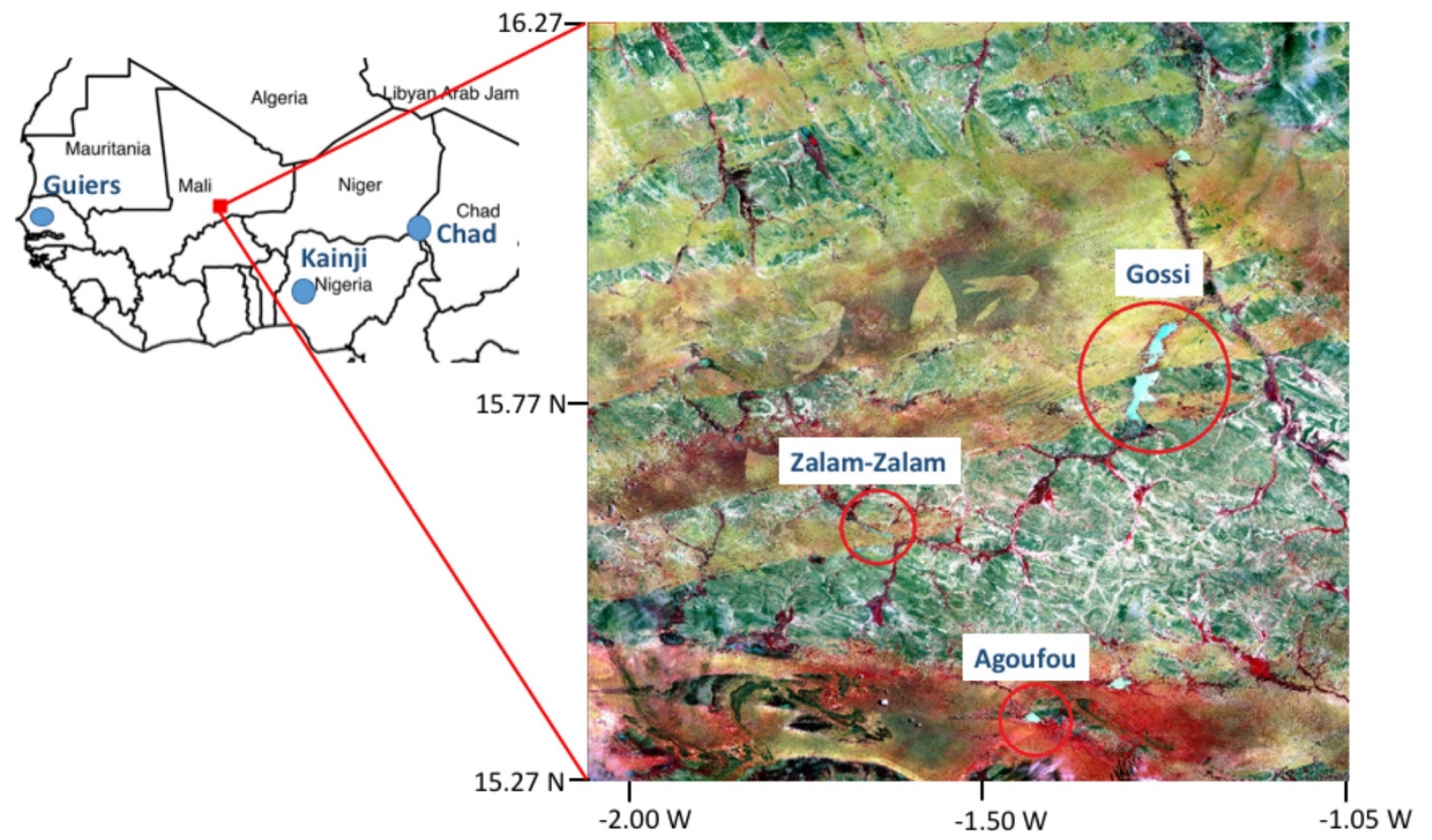

Fig. 1: Study region and main lakes analyzed in this study. The image background is a false color composite (IR,R, G) from the Sentinel2 sensor.

\subsection{SWOT synthetic data}

Synthetic SWOT data have been produced using the SWOT High Resolution (SWOT-HR) simulator developed by the NASA Jet Propulsion Laboratory (JPL) and installed at Centre National d'Etudes Spatiales (CNES).

The basic steps performed by SWOT-HR to produce synthetic data and retrieve water levels are summarized below (see $[20,36]$ for more details of the simulator use). First, synthetic radar interferograms are produced taking into account only layover errors (i.e. errors due to the mixing of backscatter signals from two different ground locations at the same distance from the satellite [20]). Second, noise, dependent on the geometrical configuration (position within the swath), land/water contrast, and instrumental parameters, is added. Third, from the noisy interferograms, the simulator creates pixel cloud with phase difference and backscattering power. Water levels are then retrieved from the phase difference. Additionally, the simulator can also perform water classification based on the assumption that, at low incident angles, backscattering from water will be higher than from land (see [20] and references within). Finally radar coordinates are translated into geographical coordinates and the target is geolocated.

The simulator inputs used are a Digital Elevation Model (DEM) of the study area, including a precise bathymetry of the water body, and a raster with surface water levels and extent. For this study, the input DEM was constructed combining the DEM provided by SRTM3 with a lake bathymetry derived by the combination of in-situ water levels, water contours obtained by supervised classification of high resolution optical remote sensing images and in-situ bathymetry for the bottom of the lake (see [2] for more details). In-situ water levels are provided by the AMMACATCH observatory and they are freely available via its database (http://bd.amma-catch.org). They are measured about every 10 days during the wet season and monthly during the dry season using a manual reading scale with an accuracy of $2 \mathrm{~cm}[2]$.

In this study, only layover, instrument noise, land/water contrast and water classification errors have been taken into account as source of potential errors in retrieved SWOT water elevations. Other sources of errors (see [23] for more information) have not been considered.

\subsection{Satellite auxiliary data}

\section{GPM DPR data}

Data from the Global Precipitation Mission (GPM, [37]), from the Dual-frequency Precipitation Radar (DPR) instrument, were used to investigate the backscattering coefficient variability over land and water in this region in the $\mathrm{Ka}$ band at low incident angles. All GPM-DPR data for the year 2015 were downloaded from the NASA MIRADOR site (http://pmm.nasa.gov/data-access/downloads/gpm). From these 
data the surface reflectivity variables were extracted over an area of $1^{\circ} \times 1^{\circ}$ in the Gourma region and over three major lakes in the Sahel (the Guiers lake in Senegal, the Kanji reservoir in Nigeria and the Chad lake). For this study we used the sigma Zero Corrected variable, noted thereafter as $\sigma^{0}$, that gives the surface backscattering cross-section, in decibel, corrected for the attenuation by precipitation. In addition, information on the zenithal angle (local Zenith Angle), and the land surface classification (land Surface Type) were also extracted.

\section{Sentinel-2 data}

Data from the Sentinel-2 optical sensor were employed for water classification in the study area. Data were downloaded form the PEPS server (https://peps.cnes.fr/rocket/\#/home). Land cover classification was performed using the ENVI software, version 4.2 (Exelis Visual Information Solutions, Boulder, Colorado) and maximum likelihood classifier on the visible and near infrared bands (bands $1,3,4,8$ at $10 \mathrm{~m}$ spatial resolution) and the middle infrared bands (bands 11 and 12 at $20 \mathrm{~m}$ spatial resolution, resampled at $10 \mathrm{~m}$ spatial resolution) of Sentinel-2 level 1C products.
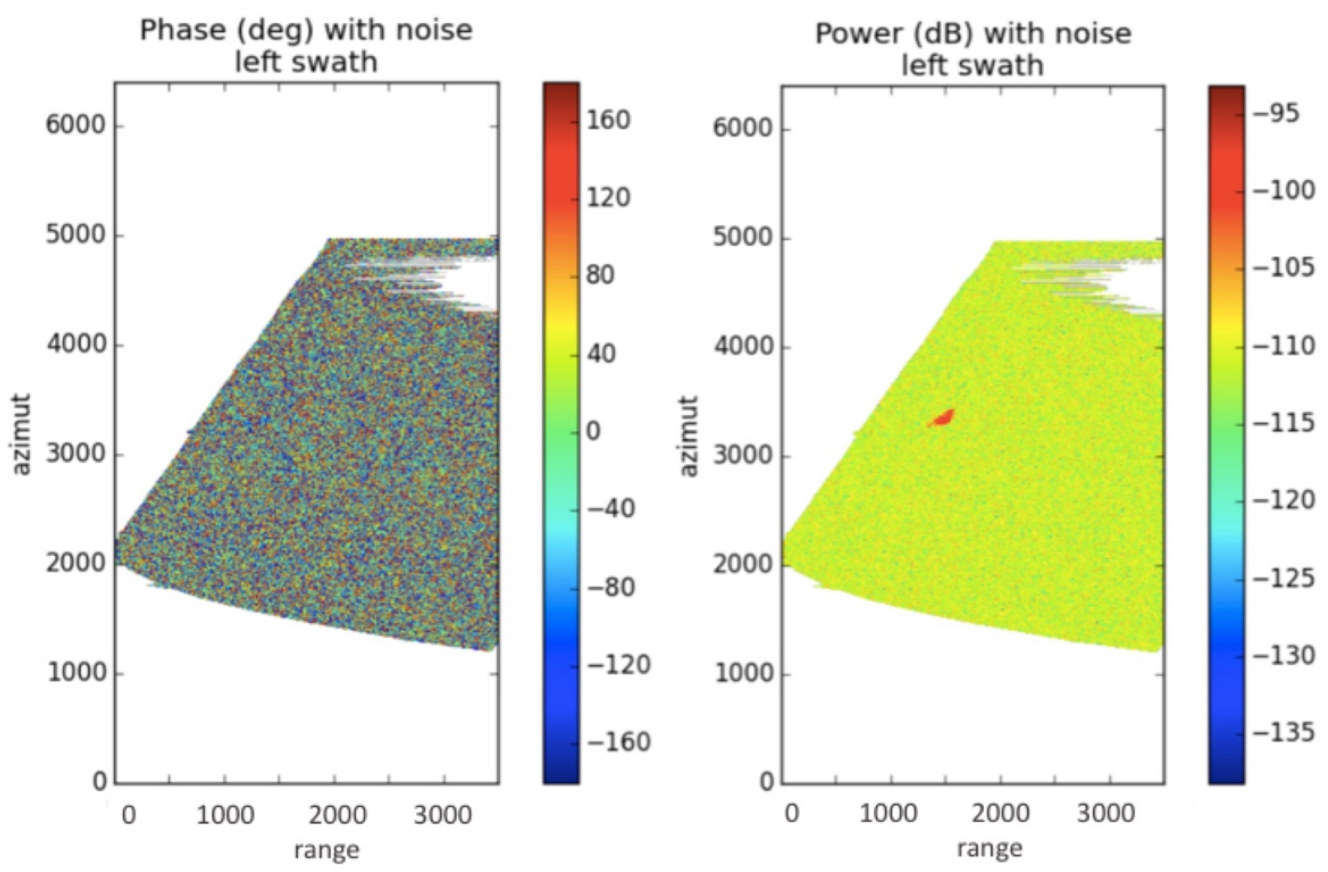

Fig. 2: Phase and power by SWOT_HR on the Agoufou lake as a function of azimut and range (in pixel count)

\section{RESULTS}

\subsection{SWOT-HR retrieved water levels}

\section{Agoufou lake}

An example of phase change and amplitude simulated by SWOT-HR for the Agoufou lake (only viewed by the left swath of orbit $\mathrm{n} 003$ with a look angle equal to 2.7) is reported in Fig. 2. with the corresponding retrieved heights in Fig. 3.

Averaging the retrieved heights (from the SWOT data cloud) over the predefined lake's surface allowed retrieving mean lake water level at a given date. Simulated SWOT data, with a revisit period of 21 days, allow monitoring quite closely the seasonal cycle (Fig. 4) since the errors on the retrieved values are much smaller than the seasonal variation of the lake water level. The maximum absolute error on retrieved average height is equal to $4.3 \mathrm{~cm}$ and it is obtained at the end of the dry season when the lake size is the smallest (about $100 \mathrm{ha}$ ) and provides, therefore, less data points to average. The relatively low value of this maximum SWOT error is due to the fact that there are very few layover errors in this area, as the lake surrounding topography is quite flat.

The 21 days repeat cycle planned by SWOT [19] has been found to be sufficient to monitor the seasonal variability in water level, especially in the dry season, when water decreases steadily and water resource shortage is maximum. 
The position of the observed lake within the satellite swath plays also a role, with more precise retrievals obtained in the middle of the swath corresponding to looking angles at about $2-2.5^{\circ}$ (Fig. 5). This is mainly due to KaRIn pixel random error (smallest in the middle of the swath) and the fact that pixel size varies from $\sim 70 \mathrm{~m}$ in the near range to $\sim 10$ $\mathrm{m}$ in the far range (i.e. there are less pixels to average in near range than in far range) [22].

\section{Zalam-Zalam lake}

SWOT-HR simulations performed over the ZalamZalam lake (Fig. 6) provided slightly poorer performances than for the Agoufou case, due to a less compact shape and less flat surroundings. Retrieved height errors on ZalamZalam ranged from $6.3 \mathrm{~cm}$ for orbit 003 to $15.1 \mathrm{~cm}$ for orbit 100 .

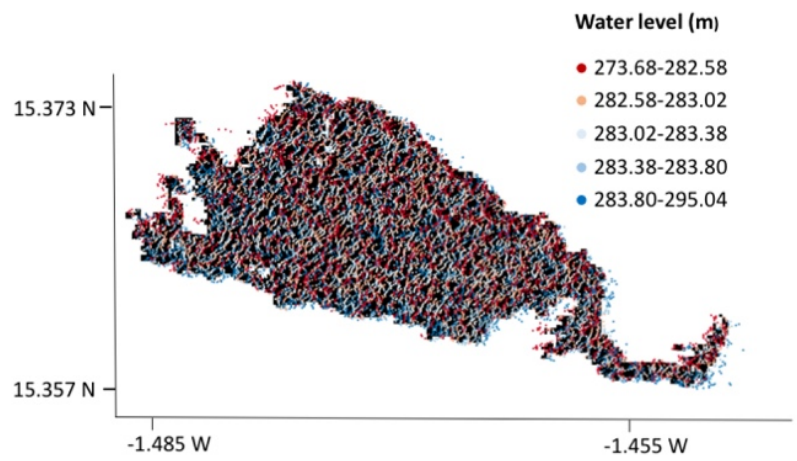

Fig. 3: Retrieved height (m) by SWOT_HR for the Agoufou lake
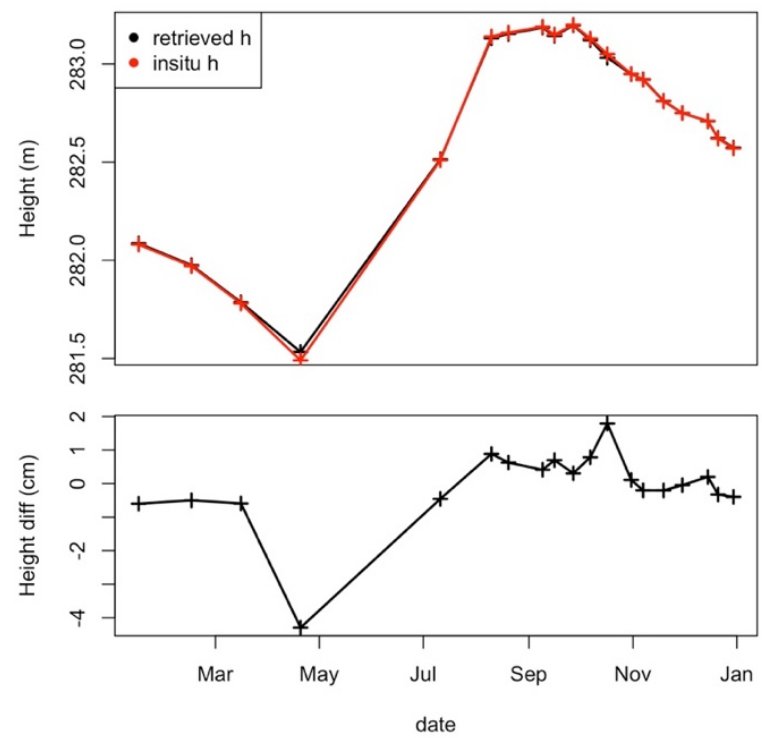

Fig. 4: top: In-situ water levels measured by AMMACATCH (blue) and SWOT_HR retrieved water levels (red) in the Agoufou lake throughout the year 2015. Bottom: difference between in-situ and SWOT-HR retrieved water levels.

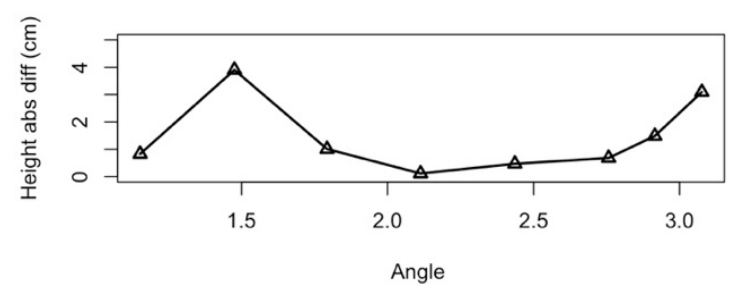

Fig. 5: Mean absolute differences between in-situ and SWOT-HR retrieved water levels as a function of the looking angle. 

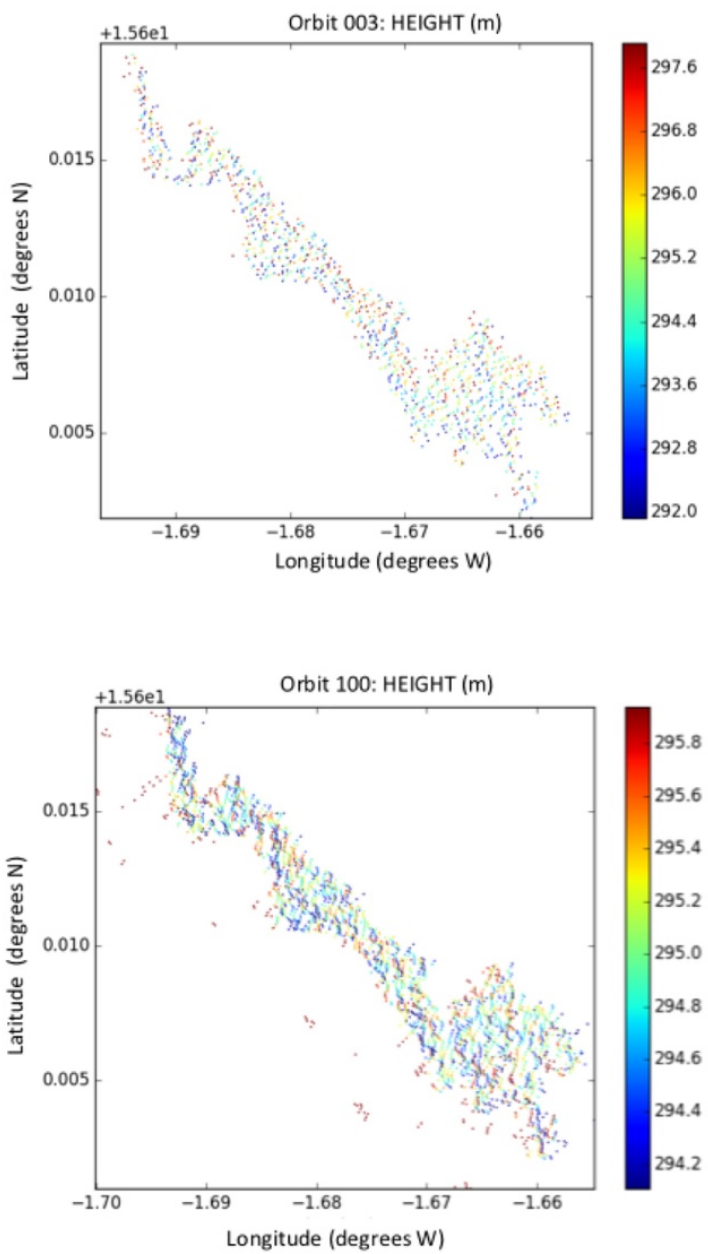

Fig. 6: Retrieved height (m) by SWOT_HR for the Zalam-Zalam lake for orbit 003 (top) and orbit 100 (bottom).

\subsection{Variability in soil and water backscattering} coefficients in the Sahelian area

The previous results were obtained by averaging height onto the exact lake surface entered in SWOT-HR. SWOT is also designed to provide water masks [19]. The water/land classification is based on the difference in backscattering coefficients for water and the surrounding soils [20]. In the example reported in Fig. 2, the differences in returned power from water (red color) and land (yellow) simulated by SWOT-HR is quite evident. This relies on default parameters for the soil surface (based on the compilation of backscattering coefficients by Ulaby and Dobson [38]), but such a contrast may not always exist with real soils, especially in the Sahel. Fig. 7 shows an example of $\sigma^{0}$ from the GPM DPR over the Gourma region surrounding the Agoufou site: apart from the dependence on the incident angle across the nadir track, important differences are found among different soil types with rocky outcrops and rocks showing higher backscattering than sandy soils. Moreover, the temporal variability in $\sigma^{0}$ over land has been also found to be very important, reaching more than $10 \mathrm{db}$ throughout the year (figure 8). 


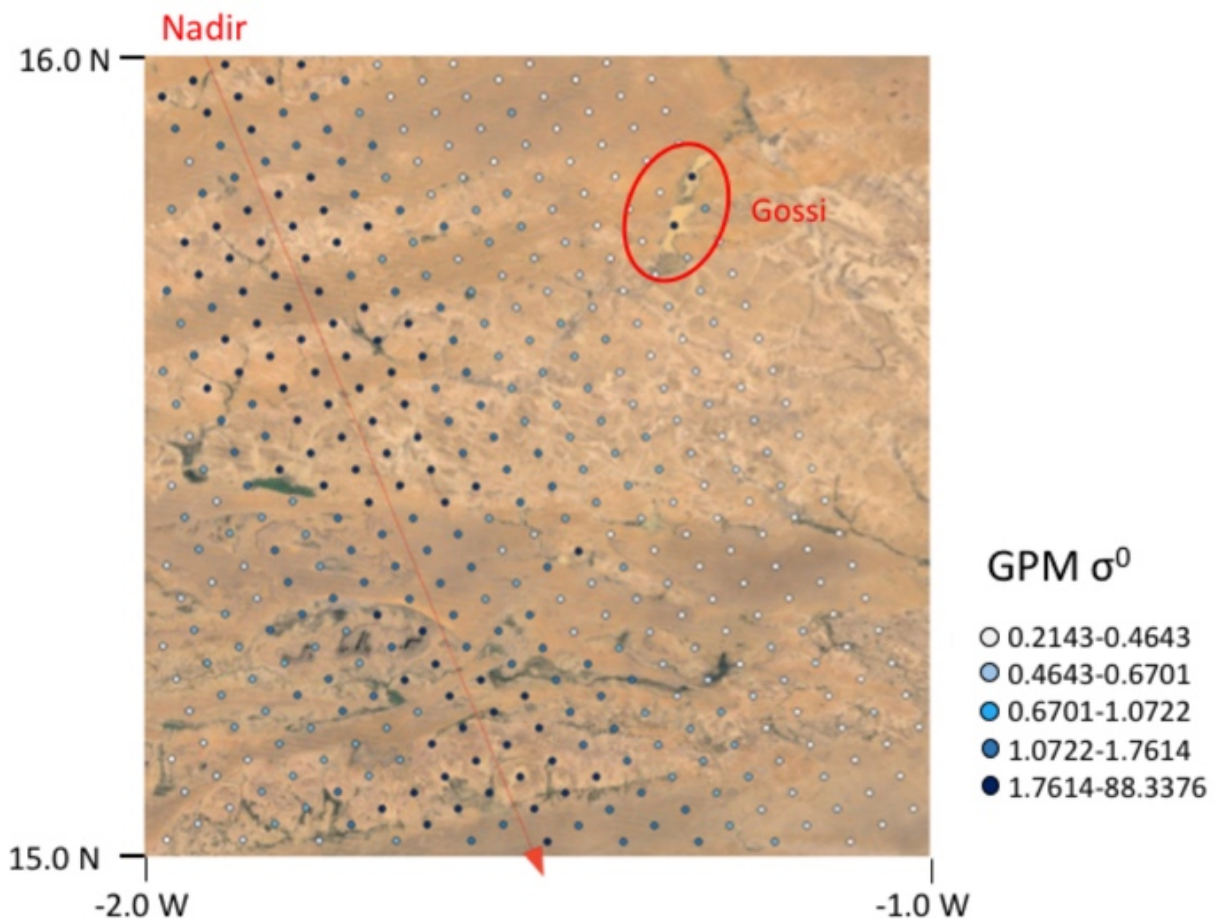

Fig. 7: GPM DPR $\sigma^{0}$ over soils in the Gourma region.

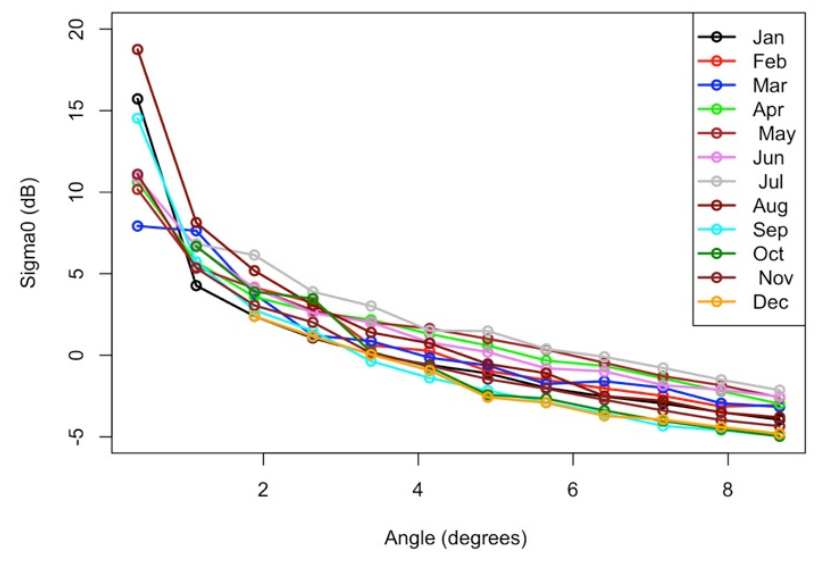

Fig. 8: Monthly variability of GPM DPR $\sigma^{0}$ as a function of the incident angle for soils in the Gourma region.

Concerning water backscattering, the Gossi lake is large enough to provide GPM DPR $\boldsymbol{\sigma}^{0}$ and, in the example reported in Fig. 7, it shows higher values than the surrounding soils. However, the coarse DPR spatial resolution (about $5 \mathrm{~km}$ ) does not allow identifying the other lakes in the region. Water backscattering has been therefore investigated over other large lakes in West Africa (Fig. 9). It was found that water (Fig. 10) generally shows higher backscattering values than soil (Fig. 8) but their difference is much lower than that obtained by the standard values provided in SWOT-HR and in some cases can become smaller than few decibels. Water backscattering from DPR ranges from about $0 \mathrm{~dB}$ to about 40 $\mathrm{dB}$ at $0^{\circ}$ incident angle and from about $-5 \mathrm{~dB}$ to about $20 \mathrm{~dB}$ at $3^{\circ}-4^{\circ}$, which is consistent with values reported by [20] for low to moderate winds. Also, we have found that the backscattering distribution with incident angle is slightly steeper during the night (not shown) when wind is usually lower.

Water and land backscattering values have been also found to slightly affect the water level retrieval: errors on retrieved water levels for the Agoufou lake were found to be slightly higher (from $0.1 \mathrm{~cm}$ to $1 \mathrm{~cm}$ ) when using $\sigma^{0}$ derived from GPM than the default parameters in SWOT_HR. This is consistent with the fact that layover is supposed to be more important when the contrast between water and land is lower [20]. 

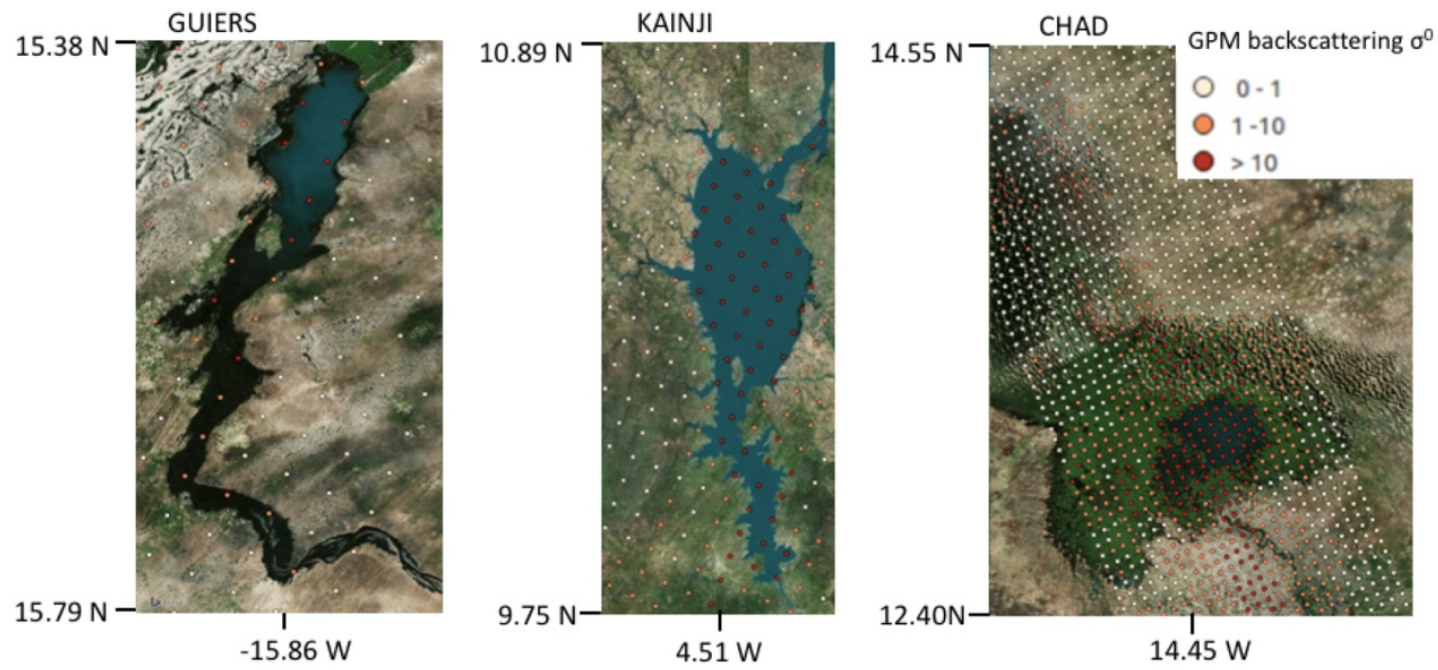

Fig. 9: GPM DPR $\sigma^{0}$ over the Guiers lake (Senegal), the Kainji reservoir (Nigeria) and the Chad lake (Chad).

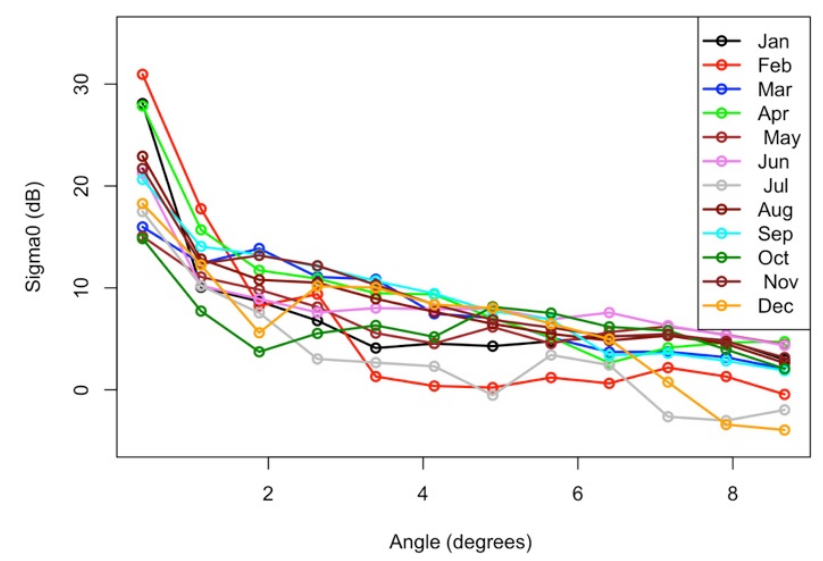

Fig. 10: Monthly variability in GPM DPR $\sigma^{0}$ as a function of the incident angle for water in the three big lakes analysed.

\subsection{SWOT coverage over the study region}

According to a supervised classification of a Sentinel2 image acquired during the wet season (24/07/2016, Fig. 1 and Fig. 11), thirteen lakes over the sixty-seven lakes of the region will be "visible" by SWOT (i.e. have an area above 1 $\mathrm{km}^{2}$, allowing a $10 \mathrm{~cm}$ vertical precision on the retrieved water level, Fig. 12). These lakes represent $76 \%$ of the total water surface. SWOT will also be able to observe smaller lakes but with a lower precision on the retrieved water levels.

\section{CONCLUDING DISCUSSION AND PERSPECTIVES}

The first application of the SWOT-HR simulator over the Sahel has shown the good potential of KaRIn for monitoring the seasonal variability in water levels.

For the Agoufou lake, an accuracy better than about $4 \mathrm{~cm}$ was achieved, well below the SWOT specifications. However, height retrieval can be more difficult for other water bodies with more elongated shapes, such as the Zalam-Zalam lake, for which an accuracy between 6.3 and $15.1 \mathrm{~cm}$ was reached. These results are consistent with those obtained using SWOT synthetic data in other regions of the world such as reservoirs in the Sacramento region, California [27] or arctic lakes [28]. Water level retrievals have also been found to be affected by the position of the lake within the satellite swath and, in a minor way, by the difference between backscattered power from water and land. In addition, we found that the 21-days repeat orbit is sufficient to correctly monitor the seasonal cycle of these water bodies, whose level range is usually a few meters [2], even if rapid events during lakes fill up may be missed.

However, the SWOT-HR simulator employed in this work only addresses geometrical (layover) errors and instrumental noise. No other error (i.e. random or systematic) has been included. A complete error budget should also take 
into account errors expected from satellite orbit, signal delay from the troposphere, vegetation effects and wind effects on the radar backscattering from water $[39,40]$.

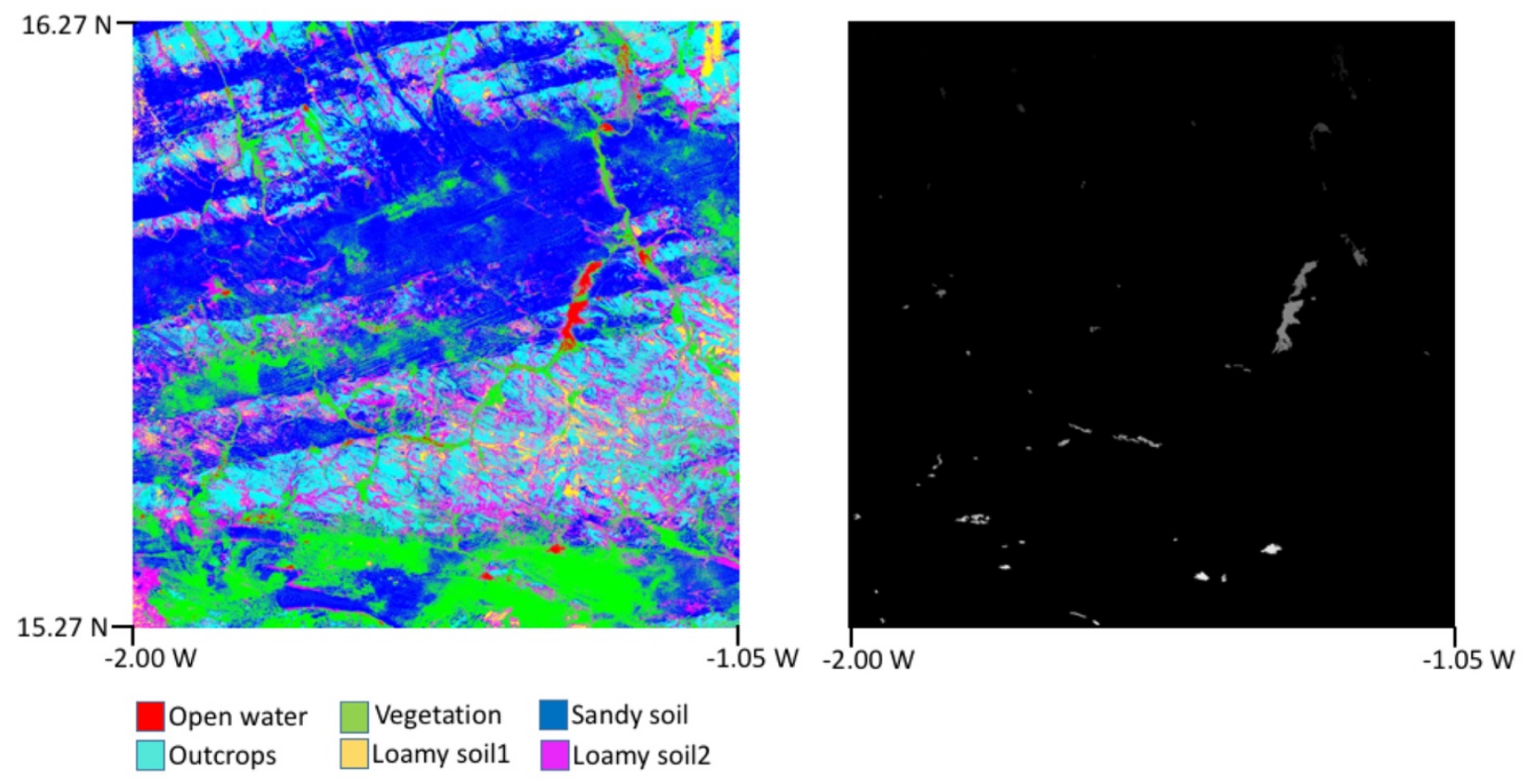

Fig. 11: left- Supervised classification of the Sentinel2 image acquired on the 24/07/2016 (see fig 1) right -segmentation of the water class (shades of gray indicate different polygons)

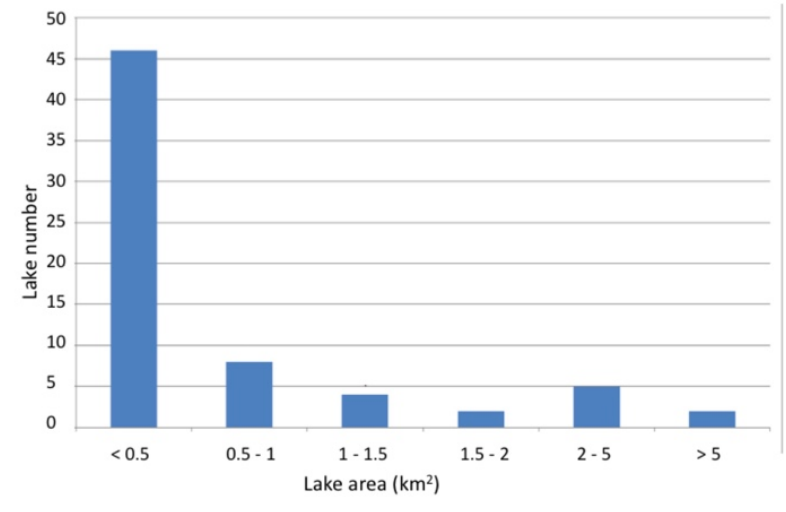

signal in the Sahel are supposed to be in the highest range of the values reported in [26].

Vegetation effects, impacting both interferometric phase and backscattering [20], should also be important in this area, given that several small lake and ponds in the Sahel are covered by trees, and could be quite challenging for SWOT. Tree cover in ponds and lakes ranges from $0 \%$ up to $60 \%$ in Sahelian ponds where this has been measured [41,42]. At a larger scale, Gardelle et al. [1] identified that about $50 \%$ of the water area in the Gourma region was covered by some vegetation, either trees, grasses, or floating vegetation. Trees typically grow in the smaller and shallower ponds, which have a shorter flood season. They are less frequent in larger water bodies. However, some dead trees, that could affect water level retrieval, may be found in the center of relatively large lakes like Agoufou, which is mainly open water. These trees are residual from the time when the lake was not permanent (see fig. 9 in [2]), and trees could survive the summer floods.

Concerning the retrieval of water masks, first estimates

Wet tropospheric delays on the radar return have been analysed in details by Mehran et al. [26] over inland reservoirs of souhtwest US and have been found to be between 4 and $18 \mathrm{~mm}$, depending on climatic conditions, elevation and surface area of the reservoir. Given the high content in the tropospheric water vapor during the monsoon season [25], tropospheric effects on the delay of the radar of land and water backscattering in the region have been derived from GPM DPR data. The water backscattering values over the three big lakes analyzed seem consistent with the values reported in the literature [20] but the situation may be different for smaller lakes and ponds. Particularly, the effects of wind on the surface roughness and therefore $\boldsymbol{\sigma}^{\mathbf{0}}$ 
should be further investigated in this region. Due to the sometime small difference in backscattering coefficients between water and soil, deriving water masks by SWOT in this region may not be straightforward. Combining SWOT water levels to lake areas derived by optical remote sensing, as in the approach followed in [2], may be a good option in this case.

Given that the Gourma region is quite representative of the Sahelian landscape in terms of relief, vegetation cover, soil types and backscattering coefficients [31,23], we believe that the results reported here can be generalized to lake and ponds within the whole Sahel, except for few exceptions where mountain formations, that can accentuate layover effects, occur.

Overall, SWOT offers a unique opportunity to monitor critical water resources in these areas and more generally in semi-arid low-instrumented countries. Beyond this, monitoring water amounts in ungauged areas is also fundamental to better understand the hydrology of these areas and to provide information to calibrate and evaluate land surface and hydrological models [34, 35]. The work by Gal et al [2] has shown that Sahelian lakes can be used as gauges to provide runoff estimates in poorly instrumented region. With SWOT data this approach could be generalized all over the Sahelian belt. In addition, estimating volume changes during the dry season, when runoff and precipitation are null, can provide precious information on surface -groundwater exchanges (infiltration of water through the bottom of lakes or water uptakes), a critical variable of the water balance that is poorly known in this region [43].

Deriving hypsometric curves for all water bodies with SWOT (by combining size and height estimations as done in [2]) shall prove extremely useful to derive water volumes from water surface area given by the Landsat archive (1972present).

Finally, estimating lake water levels and areas will allow to better understand and forecast wind driven sediment resuspension mechanisms [33], that have a strong impact on water quality variability in this area.

\section{Acknowledgements}

In situ data were provided by the AMMA-CATCH observatory. We thank all the people helping with the collection of in situ data, despite the difficulties linked to the insecurity context in northern Mali at the present time, particularly Nogmana Soumaguel and Ali Maiga as well as Eric Mougin that manages the AMMA-CATCH Mali site. We also acknowledge the CNES for funding 6 months internship of C. Rouzies.

SWOT JPL project is thanked for providing the SWOTHR simulator binaries to CNES. CNES is warmly acknowledged for funding and developing a framework to ease the use of the SWOT-HR binaries and a collection of preprocessing and post-processing tools.

\section{REFERENCES}

[1] J. Gardelle, P. Hiernaux, L. Kergoat, M. Grippa, "Less rain , more water in ponds: A remote sensing study of the dynamics of surface waters from 1950 to present in pastoral Sahel (Gourma region, Mali)"., Hydrol. Earth Syst. Sci., vol. 14, 309-324, 2010.

[2] L. Gal, M. Grippa, P. Hiernaux, C. Peugeot, E. Mougin, L. Kergoat, "Changes in lakes water volume and runoff over ungauged Sahelian watersheds". J. Hydrol. vol. 540, 1176-1188, 2016.

[3] L. Descroix et al. "Evolution of Surface Hydrology in the Sahelo-Sudanian Strip: An Updated Review”. Water, 10, 748, 2018.

[4] F. Gangneron, S. Becerra, A.H. Dia A. H. "L'étonnante diversité des ressources en eau à Hombori : entre contrastes environnementaux, pratiques locales et technologies extérieures", Tiers Monde, vol. 204, pp 109-128, 2010.

[5] E. M. Haas, E. Bartholome, B. Combal, "Time series analysis of optical remote sensing data for the mapping of temporary surface water bodies in sub-Saharan western Africa" J. Hydrol.

370, 1-4 , vol. 52-63, 2009. DOI: 10.1016/j.jhydro1.2009.02.052

[6] J.F. Pekel, A. Cottam, N. Gorelick and A.S Belward "Highresolution mapping of global surface water and its long-term changes "Nature, vol. 540 , 7633 pp 418-+, 2016

[7] M. Santoro, U. Wegmuller, C. Lamarche, S. Bontemps, P. Defournyand O. Arino, "Strengths and weaknesses of multi-year Envisat ASAR backscatter measurements to map permanent open water bodies at global scale", Rem. Sens. Environ., vol. 171, 185201, 2015

DOI: $10.1016 /$ j.rse.2015.10.031

[8] D. Eilander, F.O. Annor, L. Iannini, N. van de Giesen, "Remotely Sensed Monitoring of Small Reservoir Dynamics: A Bayesian Approach “ Rem. Sens., vol. 6, 2, 1191-1210, 2014

DOI: $10.3390 /$ rs 6021191

[9] J-F Cretaux, R. Abarca Del Rio, M. Berge-Nguyen, A. Arsen, V. Drolon, G. Clos, P. Maisongrande, "Lake volume monitoring from Space", Survey in geophysics, vol. 37, 269-305, doi: 10.1007/s10712-016-9362-6, 2016

[10] J-F Cretaux, W. Jelinski, S. Calmant, A. Kouraev, V. Vuglinski, M. Bergé Nguyen, M. C. Gennero, F. Nino, R. A. Del Rio, A. Cazenave, and P. Maisongrande, "SOLS: A lake database to monitor in the Near Real Time water level and storage variations from remote sensing data", Adv. Space Res., vol. 47, 1497-1507, 2011. doi:10.1016/j.asr.2011.01.004

[11] C. Schwatke, D. Dettmering, W. Bosch, et al. "DAHITI - an innovative approach for estimating water level time series over inland waters using multi-mission satellite altimetry" HESS, vol. $19,10,4345-4364,2015$

[12] A. K. Dubey, P. K. Gupta, P. K.S. Dutta, et al. "An improved methodology to estimate river stage and discharge using Jason-2 satellite data " J. Hydrol., vol. 529, 1776-1787, 2015.

[13] F. Baup F. Frappart and J. Maubant, "Combining highresolution satellite images and altimetry to estimate the volume of small lakes" Hydrol. Earth Syst. Sci., vol. 18, 2007-2020, 2014, doi:10.5194/hess-18-2007-2014

[14] J. Liebe, N. van de Giesen, M. Andreini, "Estimation of small reservoir storage capacities in a semi-arid environment". Phys. Chem. Earth, Parts $A / B / C$ vol. 30, 448-454, 2005.

[15] F.O. Annor, N. van de Giesen, J. Liebe, P. van de Zaag, A. Tilmant, S. N. Odai, "Delineation of small reservoirs using radar imagery in a semi-arid environment: A case study in the upper east region of Ghana". Phys. Chem. Earth, vol. 34, 309-315, $2009 .$. doi: $10.1016 /$ j.pce.2008.08.005 
[16] V. Soti, C. Puech, D. Lo Seen, A. Bertran, C. Vignolles, B. Mondet, N. Dessay, and A. Tran, "The potential for remote sensing and hydrologic modelling to assess the spatio-temporal dynamics of ponds in the Ferlo Region (Senegal)". Hydrol. Earth Syst. Sci. 14, 1449-1464, 2010.

[17] A. Ogilvie, G. Belaud, S. Massuel, M. Mulligan, P. Le Goulven, and R. Calvez "Surface water monitoring in small water bodies: potential and limits of multi-sensor Landsat time series" Hydrol. Earth Syst. Sci., vol. 22, 4349-4380, 2018.

https://doi.org/10.5194/hess-22-4349-2018

[18] C. Guilloteau, M. Gosset, C. Vignolles, M. Alcoba, Y. M. Tourre, and J.-P. Lacaux, "Impacts of satellite-based rainfall products on predicting spatial patterns of rift valley fever vectors". J. Hydrometeor., vol. 15, 1624-1635, 2014.

Doi: https://doi.org/10.1175/JHM-D-13-0134.1.

[19] S. Biancamaria, D. Lettenmaier, T. M. Pavelski, "The SWOT Mission and Its Capabilities for Land Hydrology", Surv Geophys, vol. 37, 307-337, 2016.

https://doi.org/ 10.1007/s10712-015-9346-y

[20] R. Fjørtoft, J.-M. Gaudin, N. Pourthié, J.-C. Lalaurie,A. Mallet, Member, J.-F. Nouvel, J. Martinot-Lagarde, H. Oriot, P. Borderies, C. Ruiz, and S. Daniel, "KaRIn on SWOT: Characteristics of NearNadir Ka-Band Interferometric SAR Imagery". IEEE TGRS, vol 52, 4, 2172-2185, 2014

[21] E. Rodriguez, «SWOT Science Requirements Document, JPL Doc. D-61923", 2016. Available at https://swot.jpl.nasa.gov/docs/

D-61923_SRD_Rev_A_20160318.pdf (last access 9 September 2018).

[22] D. Esteban Fernandez, "SWOT Project, mission performance and error budget". JPL Document D-79084, Revision A, https://swot.jpl.nasa.gov/docs/SWOT_D-

79084_v10Y_FINAL_REVA_06082017.pdf (last access 05 September 2018)

[23] F. Frappart, C. Fatras, E. Mougin, V. Marieu, A. T. Diepkilé, F. Blarel, P. Borderies, "Radar altimetry backscattering signatures at $\mathrm{Ka}, \mathrm{Ku}, \mathrm{C}$, and $\mathrm{S}$ bands over West Africa". Physics and Chemistry of the Earth, Parts A/B/C. , 2015. Doi: 10.1016/j.pce.2015.05.001.

[24] C. Fatras, P. Borderies, F. Frappart, E. Mougin, D. Blumstein and F. Niño, "Impact of Surface Soil Moisture Variations on Radar Altimetry Echoes at $\mathrm{Ku}$ and $\mathrm{Ka}$ Bands in Semi-Arid Areas". Remote Sensing Vol 10 N 4, 2072-4292, 2018. doi:10.3390/rs1004058

[25] O. Bock, M. N. Bouin, E. Doerflinger, P. Collard, F. Masson, R. Meynadier, et al., "West African Monsoon observed with groundbased GPS receivers during African Monsoon Multidisciplinary Analysis (AMMA)", J. Geophys. Res., vol. 113, 2008, D21105, doi:10.1029/2008JD010327.

[26] A. Mehran, E. A. Clark, and D. P. Lettenmaier, "Spatial variability of wet troposphere delays over inland water bodies". Journal of Geophysical Research: Atmospheres, vol. 122, 11,32911,346, 2017.

[27] K. C. Solander, J. T. Reager, and J. S. Famiglietti, "How well will the Surface Water and Ocean Topography (SWOT) mission observe global reservoirs?", Water Resour. Res., vol. 52, 21232140, 2016. doi:10.1002/2015WR017952

[28] H. Lee, M. Durand, H. C. Jung, D. E. Alsdorf, C. K. Shum, and Y. Sheng, "Characterization of surface water storage changes in Arctic lakes using simulated SWOT measurements", Int. J. Remote Sens., vol. 31, 3931-3953, 2010.

doi: $10.1080 / 01431161.2010 .483494$.

[29] Y. Yoon, -E. Beighley, H. Lee, T. Pavelsky, and G. Allen, "Estimating Flood Discharges in Reservoir-Regulated River Basins by Integrating Synthetic SWOT Satellite Observations and
Hydrologic Modeling” Journal of Hydrologic Engineering, vol. 214 , 2016.

[30] S. Munier, A. Polebistki, C. Brown, G. Belaud, and D. P. Lettenmaier, "SWOT data assimilation for operational reservoir management on the upper Niger River Basin", Water Resources Research, vol. 51, 2015. doi:10.1002/2014WR016157.

[31] E. Mougin, P. Hiernaux, L. Kergoat, M.Grippa, P. de Rosnay, F. Timouk et al., "The AMMA-CATCH Gourma observatory site in Mali: Relating climatic variations to changes in vegetation, surface hydrology, fluxes and natural resources ». Journal of Hydrology, vol. 375, 14-33, 2009.

[32] S. Galle, M. Grippa, C. Peugeot, I. Bouzou Moussa, B. Cappelaere, J. Demarty et al. "AMMA-CATCH, a critical zone observatory in West Africa, monitoring a region in transition" Vadose Zone Journal 2018, vol 17, N 1,

doi:10.2136/vzj2018.03.0062

[33] E. Robert, L. Kergoat, N. Soumaguel, S. Merlet, J.-M. Martinez, M. Diawara and M. Grippa "Analysis of suspended particulate matter and its drivers in Sahelian ponds and lakes by remote sensing (Landsat and MODIS): Gourma region, Mali”.

Remote Sens., 9, 1272, 2017. doi:10.3390/rs9121272

[34] L. Gal, M. Grippa, P. Hiernaux, L. Pons, L. Kergoat, L."Modeling the paradoxical evolution of runoff in pastoral Sahel. The case of the Agoufou watershed, Mali". Hydrol. Earth Syst. Sci., vol 21, 4591-4613, 2017.

[35] M. Grippa, L. Kergoat, A. Boone, C. Peugeot, J. Demarty, B. Cappelaere et al. "Modeling Surface Runoff and Water Fluxes over Contrasted Soils in the Pastoral Sahel: Evaluation of the ALMIP2 Land Surface Models over the Gourma Region in Mali" $J$. Hydromet, , vol. 18, p 1847-1866, 2017.

doi:10.1175/JHM-D-16-0170.1

[36] H. Oubanas, I. Gejadze, P.-O. Malaterre, M. Durand, R. Wei, R. P. M. Frasson, et al. « Discharge estimation in ungauged basins through variational data assimilation: The potential of the SWOT mission". Water Resources Research, vol. 54, 2405-2423, 2018. https://doi.org/10.1002/2017WR021735

[37] T. Iguchi, S. Seto, R. Meneghini, N. Yoshida, J. Awaka, M. Le, V. Chandrasekar, T. Kubota, 2010, GPM/DPR Level-2 Algorithm Theoretical Basis Document. https:

//pps.gsfc.nasa.gov/Documents/ATBD_DPR_2015_whole_a.pdf

[38] F. T. Ulaby and M. C. Dobson, Handbook of Radar Scattering Statistics for Terrain. Boston, MA, USA: Artech House, 1989.

[39] M.T. Durand, K.M . Andreadis, D.E. Alsdorf D. P. Lettenmaier, D. Moller and M. Wilson, "Estimation of bathymetric depth and slope from data assimilation of swath altimetry into a hydrodynamic model". Geophys Res Lett, vol. 35, L20401, 2008. doi:10.1029/2008GL034150

[40] S. Biancamaria, K. M. Andreadis, M. T. Durand, E.A. Clark E. Rodriguez, N. M. Mognard, D. E. Alsdorf, D. P. Lettenmaier and Y. Oudin "Preliminary characterization of SWOT hydrology error budget and global capabilities". IEEE J Sel Top Appl Earth Obs Remote Sens vol. 3, 1, 6-19, 2010.

doi:10.1109/JSTARS.2009.2034614

[41] J. P. Lacaux, Y. M. Tourre, C. Vignolles, J. A. Ndione, M. Lafaye, "Classification of ponds from high-spatial resolution remote sensing: Application to Rift Valley Fever epidemics in Senegal" Remote Sensing of Environment, vol. 106, 66-74, 2007.

[42] P. Hiernaux, L. Diarra, V. Trichon, E. Mougin, Eric, N. Soumaguel and F. Baup "Woody plant population dynamics in response to climate changes from 1984 to 2006 in Sahel (Gourma, Mali)". Journal of Hydrology, vol. 375, 2009.

doi: 10.1016/j.jhydrol.2009.01.043. 
[43] G. Favreau, C. Leduc, C. Marlin, M. Dray, J.D. Taupin, M. Massault, C. Le Gal La Salle and M. Babic "Estimate of recharge of a rising water table in semi-arid region from ${ }^{3} \mathrm{H}$ and ${ }^{14} \mathrm{C}$ modeling" Ground Water, vol. 40, 144-151, 2002.

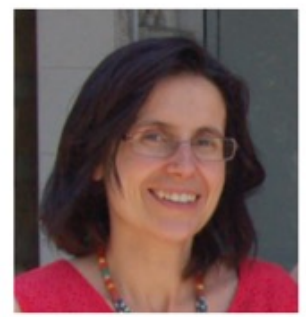

Manuela Grippa received the physics degree from the University of Milan, Italy, in 1997. She then received the Ph.D. degree from the Physics Department, Heriot-Watt University, Edinburgh, U.K., in 2001, with a dissertation on retrieval methods for atmospheric remote sounding. Her research focused then to land applications of microwave remote sensing during a first postdoctoral fellowships in radar remote sensing at the School of Earth, Environmental and Geographical Sciences, University of Edinburgh, U.K and a second one on passive microwave remote sensing at CESBIO, Toulouse, France.

She is currently working as a researcher at GET, Toulouse, France. Since the last ten years her main research interests are focused on the continental water cycle and the eco-hydrology of the Sahelian region, particularly on surface waters, using optical and radar remote sensing combined to in-situ measurements and modelling approaches.

Cyprien Rouzies received his engineering degree from the Ecole Nationale Supérieure d'Electrotechnique, d'Electronique, d'Informatique, d'Hydraulique et des Télécommunications in 2016. In his final year project was dedicated to the application of the SWOT-HR simulator to lakes in the Sahelian region.

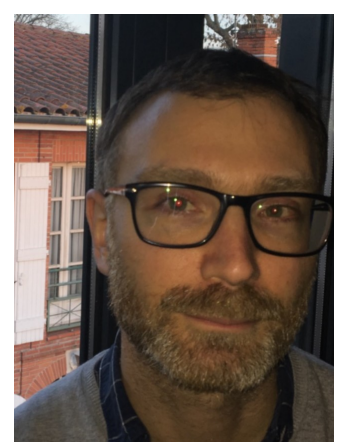

Sylvain Biancamaria received M.Eng. degree in Remote Sensing Data processing from Supaero (France) in 2005, M.Sc. degree in geosciences from University of Toulouse (France) in 2006 and Ph.D. degree in hydrology from University of Toulouse (France) in 2009. He did a post-doctoral stay at University of Washington in 2010.

He joined CNRS in 2011, as a research scientist at LEGOS (Toulouse, France). His research interests focus on water surface study using models, in situ and remote sensing data to analyze causes and consequences of water storage and fluxes variabilities of tropical watersheds. He belongs to SWOT Science Team.

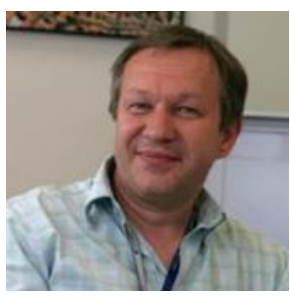

Denis Blumstein received a diploma from Ecole Centrale de Paris, France in 1982. He joined the Centre National d'Etudes Spatiale (CNES) in 1983 for which he was involved for 30 years in many space projects mainly in the field of remote sensing. In 2011 he moved to the LEGOS where his research interests focus in the use of radar altimetry in continental hydrology, coastal, and glaciology applications.

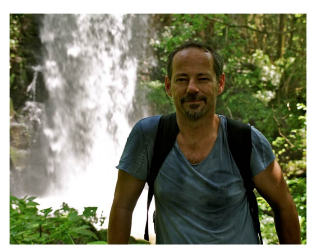

Jean-Francois Cretaux received his master degree in 1989 at the university Pierre et Marie Curie (Paris, France), his PhD in 1993 in physics sciences from the university of Toulouse (France). He joined CNES in 1994 as a research scientist at LEGOS (Toulouse, France). His research interests focus on water surface monitoring from remote sensing techniques. He is currently deputy director of LEGOS, project scientist of the Hydroweb data center, and PI of the future SWOT mission.

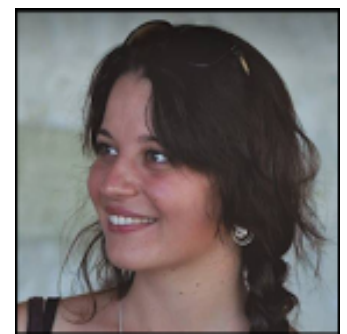

Laetitia Gal received her master degree in 2013 at the university Montpellier II (Montpellier, France). After her $\mathrm{PhD}$ in hydrological modeling at the Geoscience Environment Toulouse (Toulouse, France) in 2016, she got hired in 2017 at the French Research Institude for Sustainable Development (IRD-Montpellier, France) for a post doctoral fellowship (2 years). Her expertise lies in hydrological modeling and the impact of land use changes on hydrological processes. Her current research focuses on the impact of land use and climate changes on vineyard Mediterranean watershed.

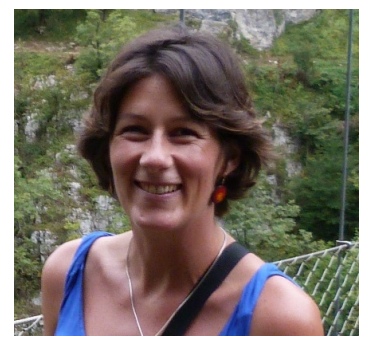

Elodie Robert received a Geography degree from the University Paris 7, France and a $\mathrm{PhD}$ degree from the Geography Department, Bordeaux 3 University, France in 2011. His research focuses on the monitoring of suspended particulate matter in surface waters using optical remote sensing particularly in West Africa. She studies these environmental changes and their impact on human health by integrating the social and health 
vulnerabilities of populations. She is currently working as a post doctorate at Geoscience Environment Toulouse, France.

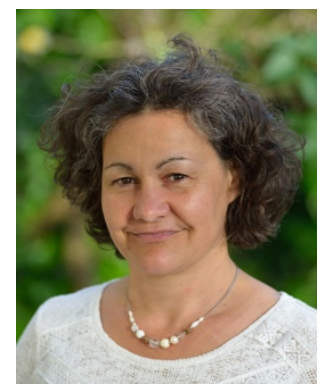

Marielle Gosset received an Eng. Degree in electronics and a $\mathrm{PhD}$ in atmospheric remote sensing in Toulouse (1992). After a postdoctoral fellowship at the University of Reading (U.K) dpt of Meteorology, and a 2 year stay in the Marshal Radar Observatory of McGill University (Canada), she got hired at the French Research Institute for Sustainable Development (IRD). She specialized in Tropical hydrometeorology using remote sensing, carried out several weather radar field experiments in West Africa. Her current research focuses on improving satellite based rainfall products for hydrology and on using mobile telephone networks for rain estimation in less developed countries.

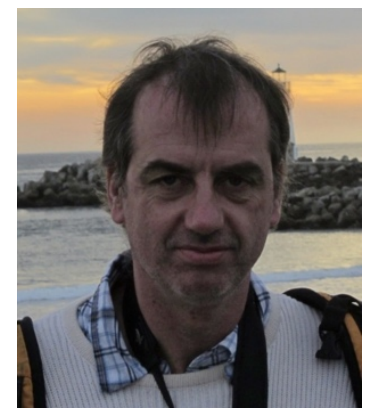

Laurent Kergoat received a diploma from Ecole Centrale de Paris, France, in 1988 and a Ph.D from Université de Toulouse, France in 1995. His research focused on vegetation observation and modelling at the global scale. He joined CNRS in 1997 (Laboratoire d'Ecologie Végétale, Toulouse), spent 1 year at NCAR Boulder, Colorado, USA in 1999, and joined CESBIO, Toulouse, in 2003, focusing on boreal zone and tropical eco-hydrology and optical remote sensing. He's currently head of the 'Hydrobiogeochemical Cycle' group at Geoscience Environment Toulouse. 